\title{
Expression of serine and glycine-related enzymes in phyllodes tumor
}

\author{
J. E. KWON ${ }^{1}$, D. H. KIM², W.-H. JUNG ${ }^{2}$, J. S. KOO $2, *$ \\ ${ }^{1}$ Department of Pathology, Ajou University School of Medicine, Suwon, Korea; ${ }^{2}$ Department of Pathology, Severance Hospital, Brain Korea 21 \\ PLUS Project for Medical Science, Yonsei University College of Medicine \\ *Correspondence: kjs1976@yuhs.ac
}

Received November 4, 2013 / Accepted February 12, 2014

\begin{abstract}
Expression patterns of proteins involved in serine and glycine metabolism, and correlations of these patterns with clinicopathologic factors in phyllodes tumor were investigated. Tissue microarrays were prepared from 203 phyllodes tumors (PT) and stained with antibodies specific for glycine decarboxylase (GLDC), phosphoserine aminotransferase 1 (PSAT1), phosphoserine phosphatase (PSPH), phosphoglycerate dehydrogenase (PHGDH), and serine hydroxymethyltransferase 1 (SHMT1). These immunohistochemical results and clinicopathologic parameters were analyzed for correlation. Numbers of benign, borderline, and malignant tumors were 155, 32, and 16, respectively. Stromal expression of PHGDH, PSAT1, PSPH, SHMT1, and GLDC increased with increasing tumor grade, and epithelial expression of SHMT1 also increased with increasing tumor grade $(\mathrm{p}<0.001$, and $\mathrm{p}=0.005$, respectively). On univariate analysis, positive stainings for stromal $\mathrm{PHGDH}$ $(\mathrm{p}<0.001)$, stromal PSAT1 $(\mathrm{p}<0.001)$, stromal PSPH $(\mathrm{p}=0.003)$, epithelial SHMT1 $(\mathrm{p}=0.001)$, stromal SHMT1 $(\mathrm{p}=0.022)$, and stromal GLDC $(\mathrm{p}<0.001)$ were each associated with shorter disease-free survival. Stromal GLDC was associated with shorter overall survival $(\mathrm{p}<0.001)$. In conclusion, expression of proteins related to serine and glycine metabolism increased with increasing histologic grade in stromal components of phyllodes tumor.
\end{abstract}

Key words: glycine, tumor grade, metabolism, phyllodes tumor, serine

Unlike normal cells, which oxidize glucose through the tricarboxylic acid (TCA) cycle and mitochondrial electron transport, cancer cells may shift into glycolysis despite presence of adequate oxygen. This shift, known as the 'Warburg effect' [1], results in accumulation of glycolytic intermediates and patterns of gene activation that may promote tumor growth. The interconnections of pathways for serine and glycine biosynthesis reveal various levels at which a shift to anerobic metabolism could support cell proliferation [2-5]. In serine biosynthesis, 3-phosphoglycerate (3PG) produced in glycolysis is oxidized by phosphoglycerate dehydrogenase (PHGDH) to 3-phosphohydroxypyruvate (pPYR), which in turn is transaminated by phosphoserine aminotransferase (PSAT) into phosphoserine (pSER), which is dephosphorylated by phosphoserine phosphatase (PSPH) into serine. In glycine metabolism, glycine decarboxylase (GLDC) catalyzes the catabolism of the glycine into methylene-tetrahydrofolate (MTF). The interconversion of serine and glycine by serine hydroxymethyltransferase (SHMT) represents a crossover point from which single carbon units flow from amino acid turnover into the synthesis of purines and pyrimidines (by way of 5 , 10-methylenetetrahydrofolate and 5-methyltetrahydrofolate) and into the essential amino acid methionine and the universal methyl-donor S-adenosylmethionine (SAM), by way of 5-MTHF. Increased availability of these substrates for growth may in part explain the advantage to the tumor in the shift to anaerobic metabolism. Recent studies show elevated PHGDH expression in breast cancer and melanoma [3, 4], and GLDC expression in lung cancer, suggesting that changes in serine and glycine metabolism may influence tumorigenesis [5].

Although phyllodes tumors (PTs) contribute only $0.3-1.5 \%$ of all breast neoplasms, they may be difficult to distinguish from fibroadenomas, which belong to the same class of fibroepithelial tumors. Both tumors present heterogeneous histologic features, however, some histologic features of the two tumors overlap [6, 7]. In addition, some PTs exhibit malignant behaviors such as occasional recurrence and hematogenous metastasis [8]. Although authors disagree on the histologic classification of PTs, the WHO criteria distinguish PTs as benign, borderline, or malignant tumors [7]. With increasing grade, the frequency of recurrence and/or probability of distant metastasis of PTs also increase. We showed previ- 
Table 1. List of enzymes and antibodies

\begin{tabular}{llll}
\hline Antibody Target & Source & Clone & Dilution \\
\hline Serine/glycine-related protein & & & Polyclonal \\
Phosphoglycerate dehydrogenase (PHGDH) & Abcam, Cambridge, UK & Polyclonal & $1: 100$ \\
Phosphoserine aminotransferase-1 (PSAT1) & Abcam, Cambridge, UK & Polyclonal & $1: 100$ \\
Phosphoserine phosphatase (PSPH) & Abcam, Cambridge, UK & Polyclonal & $1: 100$ \\
Serine hydroxymethyltransferase (SHMT) & Abcam, Cambridge, UK & Polyclonal & $1: 100$ \\
Glycine decarboxylase (GLDC) & Abcam, Cambridge, UK & & $1: 150$ \\
Proliferation related marker & & MIB-1 \\
Ki-67 & Dako Denmark AS, Glostrup, Denmark & & \\
\hline
\end{tabular}

Table 2. Clincopathologic characteristics of patients with phyllodes tumor

\begin{tabular}{|c|c|c|c|c|c|}
\hline Parameters & $\begin{array}{c}\text { Total Patients } \\
\mathrm{N}=203(100 \%)\end{array}$ & $\begin{array}{c}\text { PT, } \\
\text { Benign } \\
\mathrm{N}=155(100 \%)\end{array}$ & $\begin{array}{l}\text { PT, Borderline } \\
\mathrm{N}=32(100 \%)\end{array}$ & $\begin{array}{l}\text { PT, Malignant } \\
\mathrm{N}=16(100 \%)\end{array}$ & $P$-value \\
\hline Age (years, mean $\pm S D$ ) & $40.2 \pm 12.3$ & $38.9 \pm 12.2$ & $43.1 \pm 11.0$ & $47.6 \pm 12.9$ & 0.010 \\
\hline Tumor size $(\mathrm{cm}$, mean $\pm \mathrm{SD})$ & $4.0 \pm 2.6$ & $3.6 \pm 2.1$ & $4.2 \pm 2.5$ & $6.7 \pm 4.6$ & $<0.001$ \\
\hline Stromal cellularity & & & & & $<0.001$ \\
\hline Mild & $122(60.1)$ & $121(78.1)$ & $1(3.1)$ & $0(0.0)$ & \\
\hline Moderate & $68(33.5)$ & $34(21.9)$ & $27(84.4)$ & $7(43.8)$ & \\
\hline Marked & $13(6.4)$ & $0(0.0)$ & $4(12.5)$ & $9(56.3)$ & \\
\hline Stromal atypia & & & & & $<0.001$ \\
\hline Mild & $160(78.8)$ & $153(98.7)$ & $7(21.9)$ & $0(0.0)$ & \\
\hline Moderate & $33(16.3)$ & $2(1.3)$ & $23(71.9)$ & $8(50.0)$ & \\
\hline Marked & $10(4.9)$ & $0(0.0)$ & $2(6.3)$ & $8(50.0)$ & \\
\hline Stromal mitosis & & & & & $<0.001$ \\
\hline 0-4 / 10 HPFs & $172(84.7)$ & $155(100.0)$ & $17(53.1)$ & $0(0.0)$ & \\
\hline 5-9/ 10 HPFs & $20(9.9)$ & $0(0.0)$ & $15(46.9)$ & $5(31.3)$ & \\
\hline$\geq 10 / 10 \mathrm{HPFs}$ & $11(5.4)$ & $0(0.0)$ & $0(0.0)$ & $11(68.8)$ & \\
\hline Stromal overgrowth & & & & & $<0.001$ \\
\hline Absent & $186(91.6)$ & $155(100.0)$ & $29(90.6)$ & $2(12.5)$ & \\
\hline Present & $17(8.4)$ & $0(0.0)$ & $3(9.4)$ & $14(87.5)$ & \\
\hline Tumor margin & & & & & $<0.001$ \\
\hline Circumscribed & $182(89.7)$ & $152(98.1)$ & $24(75.0)$ & $6(37.5)$ & \\
\hline Infiltrative & $21(10.3)$ & $3(1.9)$ & $8(25.0)$ & $10(62.5)$ & \\
\hline Surgical procedure & & & & & $<0.001$ \\
\hline Local excision & $150(73.9)$ & $133(85.8)$ & $16(50.0)$ & $1(6.3)$ & \\
\hline Wide excision & $39(19.2)$ & $15(9.7)$ & $15(46.9)$ & $9(56.3)$ & \\
\hline Mastectomy & $14(6.9)$ & $7(4.5)$ & $1(3.1)$ & $6(37.5)$ & \\
\hline Radiation therapy & & & & & 0.873 \\
\hline No & $177(87.2)$ & $136(87.7)$ & $27(84.4)$ & $14(87.5)$ & \\
\hline Yes & $26(12.8)$ & $19(12.3)$ & $5(15.6)$ & $2(12.5)$ & \\
\hline Tumor recurrence & $18(8.9)$ & $5(3.2)$ & $6(18.8)$ & $7(43.8)$ & $<0.001$ \\
\hline Distant metastasis & $8(3.9)$ & $0(0.0)$ & $1(3.1)$ & $7(43.8)$ & $<0.001$ \\
\hline
\end{tabular}

PT, Phyllodes Tumor; HPFs, high-power fields

ously that expression of the glycolysis-related proteins such as Glut-1, CAIX, and MCT4 in PTs increases with increasing tumor grade [9]. We conducted the present study to investigate the expression of proteins related to serine and glycine metabolism, and to correlate these expressions with clinical and pathologic features of PT.

\section{Patients and methods}

Patient selection. Tissue samples were obtained from phyllodes tumors (PTs) removed during surgeries performed in the years 2000 to 2010, and prepared and archived at the Department of Pathology at Severance Hospital. All tis- 


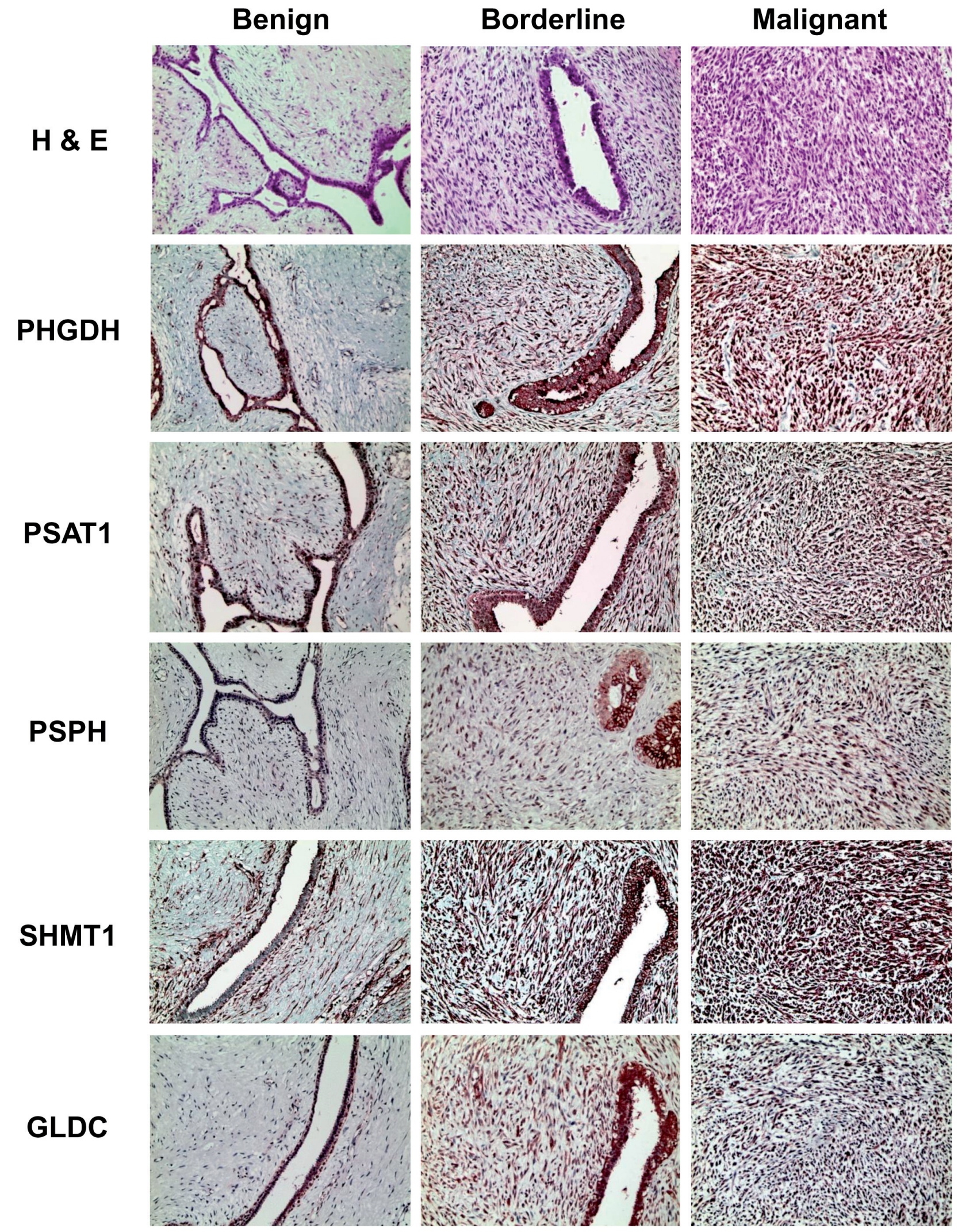

Figure 1. Expression of proteins related to serine and glycine metabolism in phyllodes tumor. As histologic grade of the tumor increased, the expression of PHGDH, PSAT1, PSPH, SHMT1, and GLDC in the stromal component also increased. 
sues were fixed in $10 \%$ buffered formalin and embedded in paraffin prior to staining with hematoxylin and eosin (H\&E). Two pathologists (JS Koo and W Jung) reviewed all of the archived H\&E slides. The PTs were graded according to criteria in the World Health Organization Classification of Tumors 2003 [7]. Clinical factors assessed were patient age, tumor recurrence, distant metastasis, and survival. The Institutional Review Board of Yonsei University Severance Hospital approved the study.

Tissue microarray (TMA). A representative area was selected fom each H\&E-stained slide and a corresponding spot was marked on the surface of the paraffin block. Using a biopsy needle, the selected area was punched out and the 5-mm tissue core was placed in a $5 \times 6$ recipient block. Two tissue cores were extracted to minimize extraction bias. Each separate tissue core was assigned a unique tissue microarray location number that was linked to a database including other clinical-pathologic data.

Immunohistochemistry. The antibodies used for immunohistochemistry in this study are shown in Table 1. All immunostainings were performed using formalin-fixed, paraffin-embedded tissue sections. Briefly, sections $5 \mu \mathrm{m}$ thick were obtained with a microtome, transferred into adhesive slides, and dried at $62{ }^{\circ} \mathrm{C}$ for $30 \mathrm{~min}$. After incubation with primary antibodies, immunodetection was performed with biotinylated antimouse immunoglobulin, followed by peroxidase-labeled streptavidin using a labeled streptavidin biotin kit with 3,3'-diaminobenzidine chromogen as substrate. The primary antibody incubation step was omitted in the negative control. Slides were counterstained with Harris

Table 3. Expression of proteins related to serine and glycine metabolism according to phyllodes tumor grade

\begin{tabular}{|c|c|c|c|c|c|}
\hline $\begin{array}{l}\text { Immunohistochemistry } \\
\text { results }\end{array}$ & $\begin{array}{l}\text { Number of Patients } \\
\qquad \begin{array}{c}\mathrm{N}=\mathbf{2 0 3} \\
(100 \%)\end{array}\end{array}$ & $\begin{array}{l}\text { PT, Benign } \\
\text { n }=155 \\
(100 \%)\end{array}$ & $\begin{array}{c}\text { PT, Borderline } \\
\mathbf{n}=\mathbf{3 2} \\
(\mathbf{1 0 0} \%)\end{array}$ & $\begin{array}{c}\text { PT, Malignant } \\
\mathbf{n}=16 \\
(100 \%)\end{array}$ & $P$-value \\
\hline PHGDH $(\mathrm{E})^{*}$ & & & & & 0.096 \\
\hline Negative & $58(31.4)$ & $51(33.6)$ & $7(25.0)$ & $0(0.0)$ & \\
\hline Positive & $127(68.6)$ & $101(66.4)$ & $21(75.0)$ & $5(100.0)$ & \\
\hline PHGDH (S) & & & & & $<0.001$ \\
\hline Negative & $165(81.3)$ & $139(89.7)$ & $22(68.8)$ & $4(25.0)$ & \\
\hline Positive & 38 (18.7) & $16(10.3)$ & $10(31.3)$ & $12(75.0)$ & \\
\hline PSAT1 $(E)^{*}$ & & & & & 0.073 \\
\hline Negative & $91(49.2)$ & $80(52.6)$ & $9(32.1)$ & $2(40.0)$ & \\
\hline Positive & $94(50.8)$ & $72(47.4)$ & $19(67.9)$ & $3(60.0)$ & \\
\hline PSAT1 (S) & & & & & $<0.001$ \\
\hline Negative & $155(76.4)$ & $133(85.8)$ & $18(56.3)$ & $4(25.0)$ & \\
\hline Positive & $48(23.6)$ & $22(14.2)$ & $14(43.8)$ & $12(75.0)$ & \\
\hline PSPH $(E)^{*}$ & & & & & 0.125 \\
\hline Negative & $82(44.3)$ & $70(46.1)$ & $12(42.9)$ & $0(0.0)$ & \\
\hline Positive & $103(55.7)$ & $82(53.9)$ & $16(57.1)$ & $5(100.0)$ & \\
\hline PSPH (S) & & & & & $<0.001$ \\
\hline Negative & $184(90.6)$ & $150(96.8)$ & $25(78.1)$ & $9(56.3)$ & \\
\hline Positive & $19(9.4)$ & $5(3.2)$ & $7(21.9)$ & $7(43.8)$ & \\
\hline SHMT1 (E)* & & & & & 0.005 \\
\hline Negative & $132(71.4)$ & $115(75.7)$ & $15(53.6)$ & $2(40.0)$ & \\
\hline Positive & $53(28.6)$ & $37(24.3)$ & $13(46.4)$ & $3(60.0)$ & \\
\hline SHMT1 (S) & & & & & $<0.001$ \\
\hline Negative & $86(42.4)$ & $79(51.0)$ & $6(18.8)$ & $1(6.3)$ & \\
\hline Positive & $117(57.6)$ & $76(49.0)$ & $26(81.3)$ & $15(93.8)$ & \\
\hline $\operatorname{GLDC}(\mathrm{E})^{*}$ & & & & & 0.575 \\
\hline Negative & $20(10.8)$ & $18(11.8)$ & $1(3.6)$ & $1(20.0)$ & \\
\hline Positive & $165(89.2)$ & $134(88.2)$ & $27(96.4)$ & $4(80.0)$ & \\
\hline GLDC (S) & & & & & $<0.001$ \\
\hline Negative & $178(87.7)$ & $146(94.2)$ & $24(75.0)$ & $8(50.0)$ & \\
\hline Positive & $25(12.3)$ & $9(5.8)$ & $8(25.0)$ & $8(50.0)$ & \\
\hline
\end{tabular}

${ }^{\star}$ Eighteen tumors without an epithelial component were excluded.

E, epithelial; S, stromal; Enzyme abbreviations as in Table 1 


\section{Benign}

\section{Glut-1}

CAIX
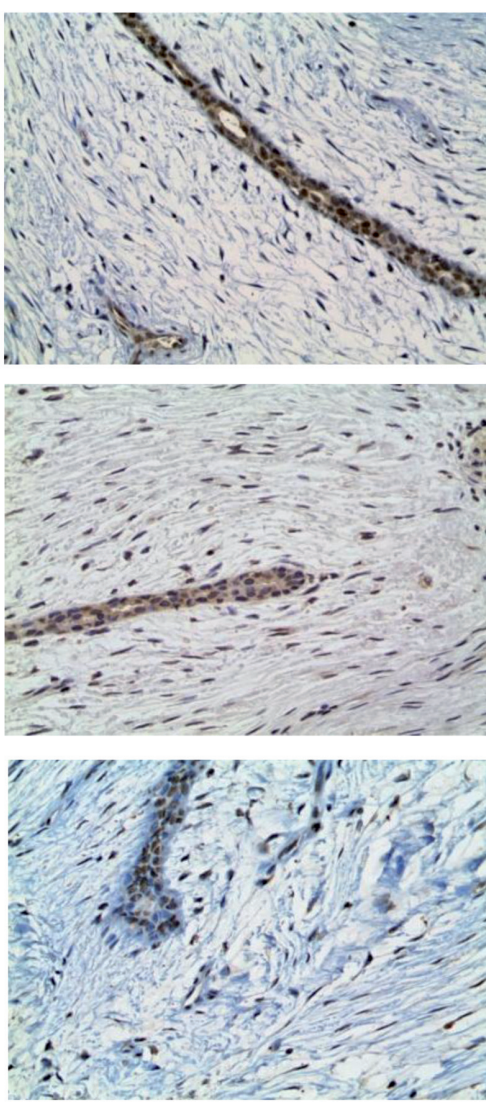

Borderline
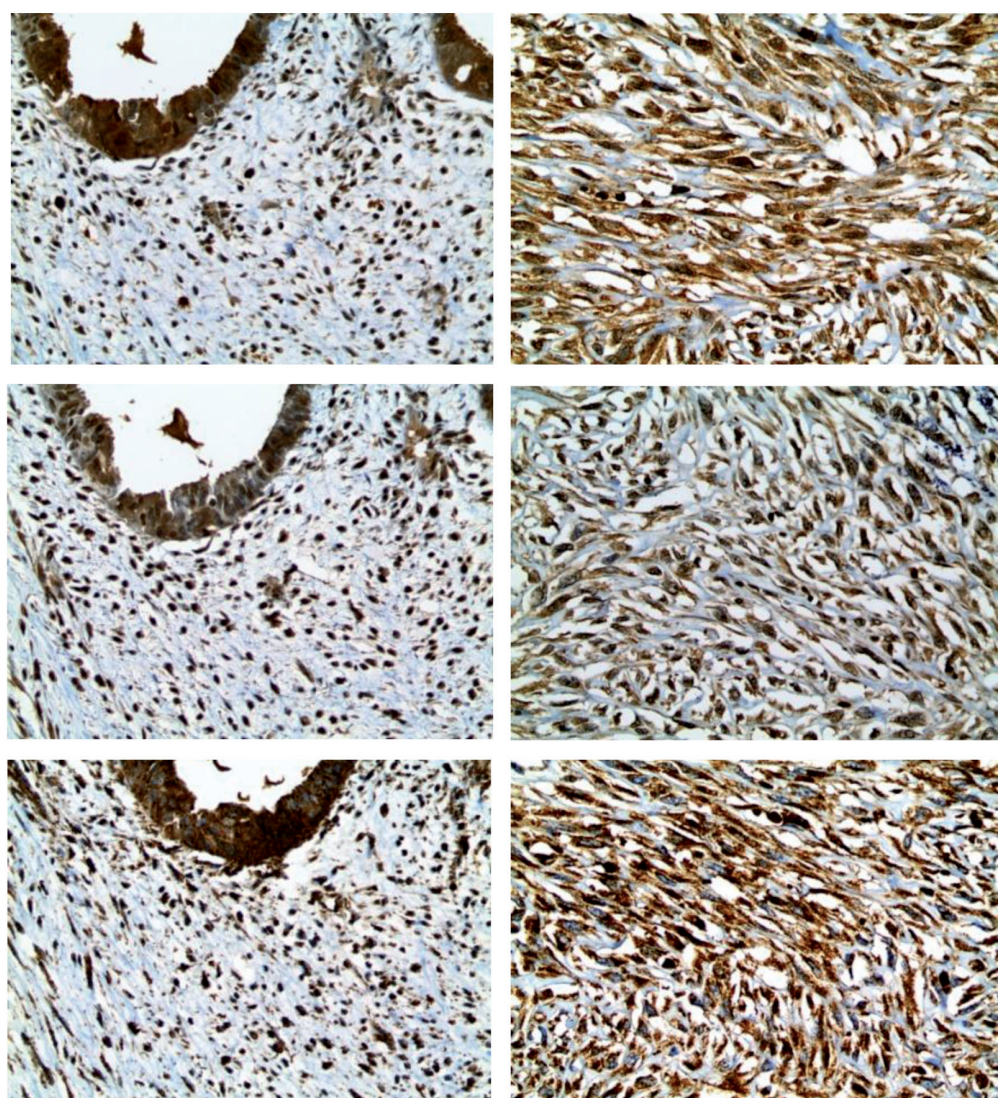

MCT4

Figure 2. Representative images for glycolysis-related proteins in phyllodes tumor.

Table 4. Correlation between expression status of serine/glycine metabolism related proteins and Ki-67 LI

\begin{tabular}{|c|c|c|c|c|c|}
\hline Parameters & $\begin{array}{c}\text { Ki-67 LI of Epithelial } \\
\text { component }^{*} \\
(\%, \text { mean } \pm \text { SD })\end{array}$ & $\mathrm{p}$-value & Parameters & $\begin{array}{c}\text { Ki-67 LI of Stromal } \\
\text { component } \\
(\%, \text { mean } \pm \text { SD })\end{array}$ & p-value \\
\hline PHGDH $(\mathrm{E})^{*}$ & & 0.019 & PHGDH (S) & & $<0.001$ \\
\hline Negative & $1.0 \pm 1.7$ & & Negative & $1.0 \pm 4.8$ & \\
\hline Positive & $2.1 \pm 3.6$ & & Positive & $7.0 \pm 12.8$ & \\
\hline PSAT1 $(\mathrm{E})^{*}$ & & 0.639 & PSAT1 (S) & & $<0.001$ \\
\hline Negative & $1.7 \pm 3.5$ & & Negative & $1.1 \pm 5.1$ & \\
\hline Positive & $1.9 \pm 2.9$ & & Positive & $5.4 \pm 11.5$ & \\
\hline PSPH $(\mathrm{E})^{*}$ & & 0.005 & PSPH (S) & & 0.051 \\
\hline Negative & $1.0 \pm 1.6$ & & Negative & $1.8 \pm 7.3$ & \\
\hline Positive & $2.4 \pm 3.9$ & & Positive & $5.3 \pm 6.8$ & \\
\hline SHMT1 (E)* & & 0.370 & SHMT1 (S) & & 0.002 \\
\hline Negative & $1.6 \pm 3.4$ & & Negative & $0.3 \pm 1.1$ & \\
\hline Positive & $2.1 \pm 2.5$ & & Positive & $3.5 \pm 9.4$ & \\
\hline $\operatorname{GLDC}(\mathrm{E})^{*}$ & & 0.260 & GLDC (S) & & $<0.001$ \\
\hline Negative & $1.0 \pm 1.8$ & & Negative & $1.1 \pm 4.7$ & \\
\hline Positive & $1.9 \pm 3.3$ & & Positive & $9.3 \pm 15.1$ & \\
\hline
\end{tabular}

* Eighteen tumors without an epithelial component were excluded.

E, epithelial; S, stromal; Enzyme abbreviations as in Table 1 
Table 5. Correlations between serine- and glycine-related proteins expressed in the epithelial component of phyllodes tumor and pathologic parameters*

\begin{tabular}{|c|c|c|c|c|c|c|c|c|c|c|c|c|c|c|c|}
\hline \multirow[t]{2}{*}{ Parameters } & \multicolumn{3}{|c|}{ PHGDH } & \multicolumn{3}{|c|}{ PSAT1 } & \multicolumn{3}{|c|}{ PSPH } & \multicolumn{3}{|c|}{ SHMT1 } & \multicolumn{3}{|c|}{ GLDC } \\
\hline & - & + & $\begin{array}{c}P- \\
\text { value } \dagger\end{array}$ & - & + & $\begin{array}{c}P- \\
\text { value } \dagger\end{array}$ & - & + & $\begin{array}{c}P- \\
\text { value } \dagger\end{array}$ & - & + & $\begin{array}{c}P- \\
\text { value } \dagger\end{array}$ & - & + & $\begin{array}{c}P_{-} \\
\text {value } \dagger\end{array}$ \\
\hline Stromal cellularity & & & 0.420 & & & 1.810 & & & 0.280 & & & 0.230 & & & 0.576 \\
\hline Mild & $\begin{array}{c}44 \\
(75.9)\end{array}$ & $\begin{array}{c}75 \\
(59.1)\end{array}$ & & $\begin{array}{c}63 \\
(69.2)\end{array}$ & $\begin{array}{c}56 \\
(59.6)\end{array}$ & & $\begin{array}{c}60 \\
(73.2)\end{array}$ & $\begin{array}{c}59 \\
(57.3)\end{array}$ & & $\begin{array}{c}92 \\
(69.7)\end{array}$ & $\begin{array}{c}27 \\
(50.9)\end{array}$ & & $\begin{array}{c}17 \\
(85.0)\end{array}$ & $\begin{array}{c}102 \\
(61.8)\end{array}$ & \\
\hline Moderate & $\begin{array}{c}13 \\
(22.4)\end{array}$ & $\begin{array}{c}47 \\
(37.0)\end{array}$ & & $\begin{array}{c}25 \\
(27.5)\end{array}$ & $\begin{array}{c}35 \\
(37.2)\end{array}$ & & $\begin{array}{c}21 \\
(25.6)\end{array}$ & $\begin{array}{c}39 \\
(37.9)\end{array}$ & & $\begin{array}{c}37 \\
(28.0)\end{array}$ & $\begin{array}{c}23 \\
(43.4)\end{array}$ & & $\begin{array}{c}3 \\
(15.0)\end{array}$ & $\begin{array}{c}57 \\
(34.5)\end{array}$ & \\
\hline Marked & $\begin{array}{c}1 \\
(1.7)\end{array}$ & $\begin{array}{c}5 \\
(3.9)\end{array}$ & & $\begin{array}{c}3 \\
(3.3)\end{array}$ & $\begin{array}{c}3 \\
(3.2)\end{array}$ & & $\begin{array}{c}1 \\
(1.2)\end{array}$ & $\begin{array}{c}5 \\
(4.9)\end{array}$ & & $\begin{array}{c}3 \\
(2.3)\end{array}$ & $\begin{array}{c}3 \\
(5.7)\end{array}$ & & $\begin{array}{c}0 \\
(0.0)\end{array}$ & $\begin{array}{c}6 \\
(3.6)\end{array}$ & \\
\hline Stromal atypia & & & 2.105 & & & 1.505 & & & 1.850 & & & 0.005 & & & 3.635 \\
\hline Mild & $\begin{array}{c}52 \\
(89.7)\end{array}$ & $\begin{array}{c}105 \\
(82.7)\end{array}$ & & $\begin{array}{c}81 \\
(89.0)\end{array}$ & $\begin{array}{c}76 \\
(80.9)\end{array}$ & & $\begin{array}{c}73 \\
(89.0)\end{array}$ & $\begin{array}{c}84 \\
(81.6)\end{array}$ & & $\begin{array}{c}120 \\
(90.9)\end{array}$ & $\begin{array}{c}37 \\
(69.8)\end{array}$ & & $\begin{array}{c}18 \\
(90.0)\end{array}$ & $\begin{array}{c}139 \\
(84.2)\end{array}$ & \\
\hline Moderate & $\begin{array}{c}5 \\
(8.6)\end{array}$ & $\begin{array}{c}20 \\
(15.7)\end{array}$ & & $\begin{array}{c}9 \\
(9.9)\end{array}$ & $\begin{array}{c}16 \\
(17.0)\end{array}$ & & $\begin{array}{c}8 \\
(9.8)\end{array}$ & $\begin{array}{c}17 \\
(16.5)\end{array}$ & & $\begin{array}{c}10 \\
(7.6)\end{array}$ & $\begin{array}{c}15 \\
(28.3)\end{array}$ & & $\begin{array}{c}2 \\
(10.0)\end{array}$ & $\begin{array}{c}23 \\
(13.9)\end{array}$ & \\
\hline Marked & $\begin{array}{c}1 \\
(1.7)\end{array}$ & $\begin{array}{c}2 \\
(1.6)\end{array}$ & & $\begin{array}{c}1 \\
(1.1)\end{array}$ & $\begin{array}{c}2 \\
(2.1)\end{array}$ & & $\begin{array}{c}1 \\
(1.2)\end{array}$ & $\begin{array}{c}2 \\
(1.9)\end{array}$ & & $\begin{array}{c}2 \\
(1.5)\end{array}$ & $\begin{array}{c}1 \\
(1.9)\end{array}$ & & $\begin{array}{c}0 \\
(0.0)\end{array}$ & $\begin{array}{c}3 \\
(1.8)\end{array}$ & \\
\hline Stromal mitosis & & & 2.865 & & & 0.955 & & & 2.070 & & & 0.010 & & & 3.790 \\
\hline 0-4/10 HPFs & $\begin{array}{c}54 \\
(93.1)\end{array}$ & $\begin{array}{c}114 \\
(89.8)\end{array}$ & & $\begin{array}{c}86 \\
(94.5)\end{array}$ & $\begin{array}{c}82 \\
(87.2)\end{array}$ & & $\begin{array}{c}76 \\
(92.7)\end{array}$ & $\begin{array}{c}92 \\
(89.3)\end{array}$ & & $\begin{array}{c}126 \\
(95.5)\end{array}$ & $\begin{array}{c}42 \\
(79.2)\end{array}$ & & $\begin{array}{c}19 \\
(95.0)\end{array}$ & $\begin{array}{c}149 \\
(90.3)\end{array}$ & \\
\hline 5-9/10 HPFs & $\begin{array}{c}4 \\
(6.9)\end{array}$ & $\begin{array}{c}11 \\
(8.7)\end{array}$ & & $\begin{array}{c}4 \\
(4.4)\end{array}$ & $\begin{array}{c}11 \\
(11.7)\end{array}$ & & $\begin{array}{c}6 \\
(7.3)\end{array}$ & $\begin{array}{c}9 \\
(8.7)\end{array}$ & & $\begin{array}{c}5 \\
(3.8)\end{array}$ & $\begin{array}{c}10 \\
(18.9)\end{array}$ & & $\begin{array}{c}1 \\
(5.0)\end{array}$ & $\begin{array}{c}14 \\
(8.5)\end{array}$ & \\
\hline$\geq 10 / 10 \mathrm{HPFs}$ & $\begin{array}{c}0 \\
(0.0)\end{array}$ & $\begin{array}{c}2 \\
(1.6)\end{array}$ & & $\begin{array}{c}1 \\
(1.1)\end{array}$ & $\begin{array}{c}1 \\
(1.1)\end{array}$ & & $\begin{array}{c}0 \\
(0.0)\end{array}$ & $\begin{array}{c}2 \\
(1.9)\end{array}$ & & $\begin{array}{c}1 \\
(0.8)\end{array}$ & $\begin{array}{c}1 \\
(1.9)\end{array}$ & & $\begin{array}{c}0 \\
(0.0)\end{array}$ & $\begin{array}{c}2 \\
(1.2)\end{array}$ & \\
\hline Stromal overgrowth & & & 1.190 & & & 2.900 & & & 0.595 & & & 0.710 & & & 2.715 \\
\hline Absent & $\begin{array}{c}58 \\
(100.0)\end{array}$ & $\begin{array}{c}124 \\
(97.6)\end{array}$ & & $\begin{array}{c}90 \\
(98.9)\end{array}$ & $\begin{array}{c}92 \\
(97.9)\end{array}$ & & $\begin{array}{c}82 \\
(100.0)\end{array}$ & $\begin{array}{c}100 \\
(97.1)\end{array}$ & & $\begin{array}{c}131 \\
(99.2)\end{array}$ & $\begin{array}{c}51 \\
(96.2)\end{array}$ & & $\begin{array}{c}20 \\
(100.0)\end{array}$ & $\begin{array}{c}162 \\
(98.2)\end{array}$ & \\
\hline Present & $\begin{array}{c}0 \\
(0.0)\end{array}$ & $\begin{array}{c}3 \\
(2.4)\end{array}$ & & $\begin{array}{c}1 \\
(1.1)\end{array}$ & $\begin{array}{c}2 \\
(2.1)\end{array}$ & & $\begin{array}{c}0 \\
(0.0)\end{array}$ & $\begin{array}{c}3 \\
(2.9)\end{array}$ & & $\begin{array}{c}1 \\
(0.8)\end{array}$ & $\begin{array}{c}2 \\
(3.8)\end{array}$ & & $\begin{array}{c}0 \\
(0.0)\end{array}$ & $\begin{array}{c}3 \\
(1.8)\end{array}$ & \\
\hline Tumor margin & & & 0.045 & & & 3.110 & & & 0.095 & & & 0.330 & & & 3.230 \\
\hline Circumscribed & $\begin{array}{c}58 \\
(100.0)\end{array}$ & $\begin{array}{c}113 \\
(89.0)\end{array}$ & & $\begin{array}{c}85 \\
(93.4)\end{array}$ & $\begin{array}{c}86 \\
(91.5)\end{array}$ & & $\begin{array}{c}80 \\
(97.6)\end{array}$ & $\begin{array}{c}91 \\
(88.3)\end{array}$ & & $\begin{array}{c}125 \\
(94.7)\end{array}$ & $\begin{array}{c}46 \\
(86.8)\end{array}$ & & $\begin{array}{c}19 \\
(95.0)\end{array}$ & $\begin{array}{c}152 \\
(92.1)\end{array}$ & \\
\hline Infiltrative & $\begin{array}{c}0 \\
(0.0)\end{array}$ & $\begin{array}{c}14 \\
(11.0)\end{array}$ & & $\begin{array}{c}6 \\
(6.6)\end{array}$ & $\begin{array}{c}8 \\
(8.5)\end{array}$ & & $\begin{array}{c}2 \\
(2.4)\end{array}$ & $\begin{array}{c}12 \\
(11.7)\end{array}$ & & $\begin{array}{c}7 \\
(5.3)\end{array}$ & $\begin{array}{c}7 \\
(13.2)\end{array}$ & & $\begin{array}{c}1 \\
(5.0)\end{array}$ & $\begin{array}{c}13 \\
(7.9)\end{array}$ & \\
\hline Tumor recurrence & & & 1.285 & & & 1.280 & & & 0.815 & & & 0.015 & & & 2.495 \\
\hline Absent & $\begin{array}{c}56 \\
(96.6)\end{array}$ & $\begin{array}{c}117 \\
(92.1)\end{array}$ & & $\begin{array}{c}87 \\
(95.6)\end{array}$ & $\begin{array}{c}86 \\
(91.5)\end{array}$ & & $\begin{array}{c}79 \\
(96.3)\end{array}$ & $\begin{array}{c}94 \\
(91.3)\end{array}$ & & $\begin{array}{c}128 \\
(97.0)\end{array}$ & $\begin{array}{c}45 \\
(84.9)\end{array}$ & & $\begin{array}{c}18 \\
(90.0)\end{array}$ & $\begin{array}{c}155 \\
(93.9)\end{array}$ & \\
\hline Present & $\begin{array}{c}2 \\
(3.4)\end{array}$ & $\begin{array}{c}10 \\
(7.9)\end{array}$ & & $\begin{array}{c}4 \\
(4.4)\end{array}$ & $\begin{array}{c}8 \\
(8.5)\end{array}$ & & $\begin{array}{c}3 \\
(3.7)\end{array}$ & $\begin{array}{c}9 \\
(8.7)\end{array}$ & & $\begin{array}{c}4 \\
(3.0)\end{array}$ & $\begin{array}{c}8 \\
(15.1)\end{array}$ & & $\begin{array}{c}2 \\
(10.0)\end{array}$ & $\begin{array}{c}10 \\
(6.1)\end{array}$ & \\
\hline Distant metastasis & & & 1.685 & & & 0.810 & & & 1.025 & & & 0.125 & & & 0.365 \\
\hline Absent & $\begin{array}{c}58 \\
(100.0)\end{array}$ & $\begin{array}{c}125 \\
(98.4)\end{array}$ & & $\begin{array}{c}91 \\
(100.0)\end{array}$ & $\begin{array}{c}92 \\
(97.9)\end{array}$ & & $\begin{array}{c}82 \\
(100.0)\end{array}$ & $\begin{array}{c}101 \\
(98.1)\end{array}$ & & $\begin{array}{c}132 \\
(100.0)\end{array}$ & $\begin{array}{c}51 \\
(96.2)\end{array}$ & & $\begin{array}{c}19 \\
(95.0)\end{array}$ & $\begin{array}{c}164 \\
(99.4)\end{array}$ & \\
\hline Present & $\begin{array}{c}0 \\
(0.0) \\
\end{array}$ & $\begin{array}{c}2 \\
(1.6)\end{array}$ & & $\begin{array}{c}0 \\
(0.0) \\
\end{array}$ & $\begin{array}{c}2 \\
(2.1)\end{array}$ & & $\begin{array}{c}0 \\
(0.0)\end{array}$ & $\begin{array}{c}2 \\
(1.9)\end{array}$ & & $\begin{array}{c}0 \\
(0.0) \\
\end{array}$ & $\begin{array}{c}2 \\
(3.8)\end{array}$ & & $\begin{array}{c}1 \\
(5.0)\end{array}$ & $\begin{array}{c}1 \\
(0.6)\end{array}$ & \\
\hline
\end{tabular}

${ }^{\star}$ Eighteen cases without an epithelial component were excluded.

$\dagger P$-values are corrected for multiple testing using the Bonferroni correction.

HPF, high-powered fields; Enzyme abbreviations as in Table 1

hematoxylin. Immunohistochemical markers for GLDC, PSAT, PSPH, PHGDH, and SHMT1 were assessed by light microscopy. The staining results were semi-quantitatively scored by multiplying the proportion of stained cells by immunostaining intensity. The proportion of cells stained was categorized as 0 (negative), 1 ( $<30 \%$ of tumor cells), or 2 ( $>30 \%$ of tumor cells), and the intensity was categorized as 0 (negative), 1 (weak), 2 (moderate), or 3 (strong). The total score was determined as negative (0 to 1 ) or positive (2 to 6) [10]. Ki-67 labeling indices (LI) were scored by 

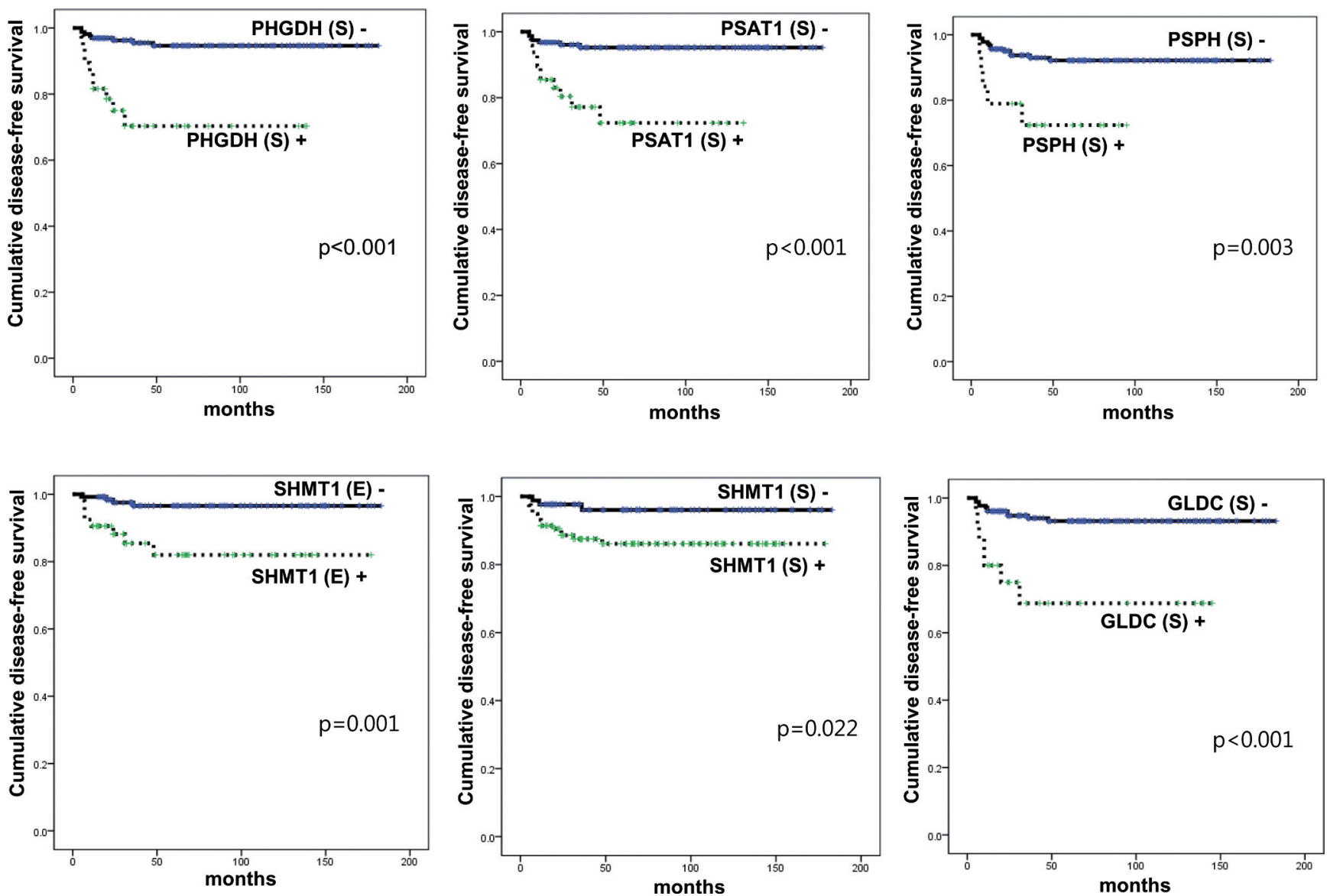

Figure 3. Disease-free survival according to expression of proteins related to serine and glycine metabolism.

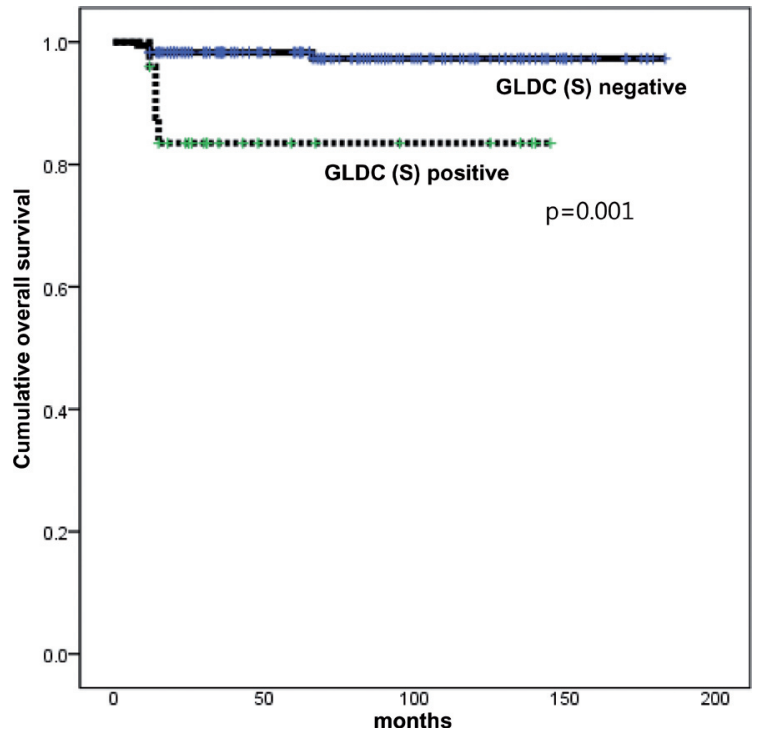

Figure 4. Overall survival according to status of GLDC in stromal component of phyllodes tumor. counting the number of positively stained nuclei and is expressed as a percentage of total tumor cells.

Statistical analysis. Data were analyzed using SPSS for Windows, Version 12.0 (SPSS Inc., Chicago, IL, USA). For determination of statistical significance, Student's $t$ and Fisher's exact tests were used for continuous and categorical variables, respectively. A p-value less than 0.05 was considered significant. Time to tumor recurrence was evaluated using Kaplan-Meier survival curves and the log-rank test. Multivariate regression analysis was performed using Cox proportional hazards model.

\section{Results}

Basal characteristics of phyllodes tumor. Table 2 shows basal characteristics of 203 patients with PTs that included 155 (76.4\%) benign, 32 (15.8\%) borderline, and 16 (7.9\%) malignant tumors. Higher tumor grade was associated with patient age $(\mathrm{p}=0.010)$, tumor size $(\mathrm{p}=<0.001)$, tumor recurrence $(\mathrm{p}<0.001)$, and distant metastasis $(\mathrm{p}<0.001)$. Eight patients developed distant metastasis, exclusively to the lung. 
Table 6. Correlations between serine- and glycine-related proteins expressed in the stromal component of phyllodes tumor and pathologic parameters

\begin{tabular}{|c|c|c|c|c|c|c|c|c|c|c|c|c|c|c|c|}
\hline \multirow[t]{2}{*}{ Parameters } & \multicolumn{3}{|c|}{ PHGDH } & \multicolumn{3}{|c|}{ PSAT1 } & \multicolumn{3}{|c|}{ PSPH } & \multicolumn{3}{|c|}{ SHMT1 } & \multicolumn{3}{|c|}{ GLDC } \\
\hline & - & + & $\begin{array}{c}P \text { - } \\
\text { value }\end{array}$ & - & + & $\begin{array}{c}P \text { - } \\
\text { value }\end{array}$ & - & + & $\begin{array}{c}P- \\
\text { value }\end{array}$ & - & + & $\begin{array}{c}P \text { - } \\
\text { value }\end{array}$ & - & + & $\begin{array}{c}P \text { - } \\
\text { value }\end{array}$ \\
\hline Stromal cellularity & & & $<0.001$ & & & $<0.001$ & & & $<0.001$ & & & $<0.001$ & & & $<0.001$ \\
\hline Mild & $\begin{array}{c}117 \\
(70.9)\end{array}$ & $\begin{array}{c}5 \\
(13.2)\end{array}$ & & $\begin{array}{c}112 \\
(72.3)\end{array}$ & $\begin{array}{c}10 \\
(20.8)\end{array}$ & & $\begin{array}{c}118 \\
(64.1)\end{array}$ & $\begin{array}{c}4 \\
(21.1)\end{array}$ & & $\begin{array}{c}71 \\
(82.6)\end{array}$ & $\begin{array}{c}51 \\
(43.6)\end{array}$ & & $\begin{array}{c}117 \\
(65.7)\end{array}$ & $\begin{array}{c}5 \\
(20.0)\end{array}$ & \\
\hline Moderate & $\begin{array}{c}44 \\
(26.7)\end{array}$ & $\begin{array}{c}24 \\
(63.2)\end{array}$ & & $\begin{array}{c}37 \\
(23.9)\end{array}$ & $\begin{array}{c}31 \\
(64.6)\end{array}$ & & $\begin{array}{c}58 \\
(31.5)\end{array}$ & $\begin{array}{c}10 \\
(52.6)\end{array}$ & & $\begin{array}{c}14 \\
(16.3)\end{array}$ & $\begin{array}{c}54 \\
(46.2)\end{array}$ & & $\begin{array}{c}55 \\
(30.9)\end{array}$ & $\begin{array}{c}13 \\
(52.0)\end{array}$ & \\
\hline Marked & $\begin{array}{c}4 \\
(2.4)\end{array}$ & $\begin{array}{c}9 \\
(23.7)\end{array}$ & & $\begin{array}{c}6 \\
(3.9)\end{array}$ & $\begin{array}{c}7 \\
(14.6)\end{array}$ & & $\begin{array}{c}8 \\
(4.3)\end{array}$ & $\begin{array}{c}5 \\
(26.3)\end{array}$ & & $\begin{array}{c}1 \\
(1.2)\end{array}$ & $\begin{array}{c}12 \\
(10.3)\end{array}$ & & $\begin{array}{c}6 \\
(3.4)\end{array}$ & $\begin{array}{c}7 \\
(28.0)\end{array}$ & \\
\hline Stromal atypia & & & $<0.001$ & & & $<0.001$ & & & $<0.001$ & & & $<0.001$ & & & $<0.001$ \\
\hline Mild & $\begin{array}{c}144 \\
(87.3)\end{array}$ & $\begin{array}{c}16 \\
(42.1)\end{array}$ & & $\begin{array}{c}137 \\
(88.4)\end{array}$ & $\begin{array}{c}23 \\
(47.9)\end{array}$ & & $\begin{array}{c}154 \\
(83.7)\end{array}$ & $\begin{array}{c}6 \\
(31.6)\end{array}$ & & $\begin{array}{c}81 \\
(94.2)\end{array}$ & $\begin{array}{c}79 \\
(67.5)\end{array}$ & & $\begin{array}{c}150 \\
(84.3)\end{array}$ & $\begin{array}{c}10 \\
(40.0)\end{array}$ & \\
\hline Moderate & $\begin{array}{c}18 \\
(10.9)\end{array}$ & $\begin{array}{c}15 \\
(39.5)\end{array}$ & & $\begin{array}{c}16 \\
(10.3)\end{array}$ & $\begin{array}{c}17 \\
(35.4)\end{array}$ & & $\begin{array}{c}24 \\
(13.0)\end{array}$ & $\begin{array}{c}9 \\
(47.4)\end{array}$ & & $\begin{array}{c}3 \\
(3.5)\end{array}$ & $\begin{array}{c}30 \\
(25.6)\end{array}$ & & $\begin{array}{c}23 \\
(12.9)\end{array}$ & $\begin{array}{c}10 \\
(40.0)\end{array}$ & \\
\hline Marked & $\begin{array}{c}3 \\
(1.8)\end{array}$ & $\begin{array}{c}7 \\
(18.4)\end{array}$ & & $\begin{array}{c}2 \\
(1.3)\end{array}$ & $\begin{array}{c}8 \\
(16.7)\end{array}$ & & $\begin{array}{c}6 \\
(3.3)\end{array}$ & $\begin{array}{c}4 \\
(21.1)\end{array}$ & & $\begin{array}{c}2 \\
(2.3)\end{array}$ & $\begin{array}{c}8 \\
(6.8)\end{array}$ & & $\begin{array}{c}5 \\
(2.8)\end{array}$ & $\begin{array}{c}5 \\
(20.0)\end{array}$ & \\
\hline Stromal mitosis & & & $<0.001$ & & & $<0.001$ & & & $<0.001$ & & & $<0.001$ & & & $<0.001$ \\
\hline 0-4/10 HPFs & $\begin{array}{c}152 \\
(92.1)\end{array}$ & $\begin{array}{c}20 \\
(52.6)\end{array}$ & & $\begin{array}{c}143 \\
(92.3)\end{array}$ & $\begin{array}{c}29 \\
(60.4)\end{array}$ & & $\begin{array}{c}165 \\
(89.7)\end{array}$ & $\begin{array}{c}7 \\
(36.8)\end{array}$ & & $\begin{array}{c}85 \\
(98.8)\end{array}$ & $\begin{array}{c}87 \\
(74.4)\end{array}$ & & $\begin{array}{c}159 \\
(89.3)\end{array}$ & $\begin{array}{c}13 \\
(52.0)\end{array}$ & \\
\hline 5-9/10 HPFs & $\begin{array}{c}10 \\
(6.1)\end{array}$ & $\begin{array}{c}10 \\
(26.3)\end{array}$ & & $\begin{array}{c}9 \\
(5.8)\end{array}$ & $\begin{array}{c}11 \\
(22.9)\end{array}$ & & $\begin{array}{c}12 \\
(6.5)\end{array}$ & $\begin{array}{c}8 \\
(42.1)\end{array}$ & & $\begin{array}{c}0 \\
(0.0)\end{array}$ & $\begin{array}{c}20 \\
(17.1)\end{array}$ & & $\begin{array}{c}14 \\
(7.9)\end{array}$ & $\begin{array}{c}6 \\
(24.0)\end{array}$ & \\
\hline$\geq 10 / 10 \mathrm{HPFs}$ & $\begin{array}{c}3 \\
(1.8)\end{array}$ & $\begin{array}{c}8 \\
(21.1)\end{array}$ & & $\begin{array}{c}3 \\
(1.9)\end{array}$ & $\begin{array}{c}8 \\
(16.7)\end{array}$ & & $\begin{array}{c}7 \\
(3.8)\end{array}$ & $\begin{array}{c}4 \\
(21.1)\end{array}$ & & $\begin{array}{c}1 \\
(1.2)\end{array}$ & $\begin{array}{c}10 \\
(8.5)\end{array}$ & & $\begin{array}{c}5 \\
(2.8)\end{array}$ & $\begin{array}{c}6 \\
(24.0)\end{array}$ & \\
\hline Stromal overgrowth & & & $<0.001$ & & & $<0.001$ & & & $<0.001$ & & & 0.001 & & & $<0.001$ \\
\hline Absent & $\begin{array}{c}160 \\
(97.0)\end{array}$ & $\begin{array}{c}26 \\
(68.4)\end{array}$ & & $\begin{array}{c}150 \\
(96.8)\end{array}$ & $\begin{array}{c}36 \\
(75.0)\end{array}$ & & $\begin{array}{c}174 \\
(94.6)\end{array}$ & $\begin{array}{c}12 \\
(63.2)\end{array}$ & & $\begin{array}{c}85 \\
(98.8)\end{array}$ & $\begin{array}{c}101 \\
(86.3)\end{array}$ & & $\begin{array}{c}169 \\
(94.9)\end{array}$ & $\begin{array}{c}17 \\
(68.0)\end{array}$ & \\
\hline Present & $\begin{array}{c}5 \\
(3.0)\end{array}$ & $\begin{array}{c}12 \\
(31.6)\end{array}$ & & $\begin{array}{c}5 \\
(3.2)\end{array}$ & $\begin{array}{c}12 \\
(25.0)\end{array}$ & & $\begin{array}{c}10 \\
(5.4)\end{array}$ & $\begin{array}{c}7 \\
(36.8)\end{array}$ & & $\begin{array}{c}1 \\
(1.2)\end{array}$ & $\begin{array}{c}16 \\
(13.7)\end{array}$ & & $\begin{array}{c}9 \\
(5.1)\end{array}$ & $\begin{array}{c}8 \\
(32.0)\end{array}$ & \\
\hline Tumor margin & & & $<0.001$ & & & 0.001 & & & $<0.001$ & & & 0.030 & & & $<0.001$ \\
\hline Circumscribed & $\begin{array}{c}154 \\
(93.3)\end{array}$ & $\begin{array}{c}28 \\
(73.7)\end{array}$ & & $\begin{array}{c}145 \\
(93.5)\end{array}$ & $\begin{array}{c}37 \\
(77.1)\end{array}$ & & $\begin{array}{c}170 \\
(92.4)\end{array}$ & $\begin{array}{c}12 \\
(63.2)\end{array}$ & & $\begin{array}{c}83 \\
(96.5)\end{array}$ & $\begin{array}{c}99 \\
(84.6)\end{array}$ & & $\begin{array}{c}166 \\
(93.3)\end{array}$ & $\begin{array}{c}16 \\
(64.0)\end{array}$ & \\
\hline Infiltrative & $\begin{array}{c}11 \\
(6.7)\end{array}$ & $\begin{array}{c}10 \\
(26.3)\end{array}$ & & $\begin{array}{c}10 \\
(6.5)\end{array}$ & $\begin{array}{c}11 \\
(22.9)\end{array}$ & & $\begin{array}{c}14 \\
(7.6)\end{array}$ & $\begin{array}{c}7 \\
(36.8)\end{array}$ & & $\begin{array}{c}3 \\
(3.5)\end{array}$ & $\begin{array}{c}18 \\
(15.4)\end{array}$ & & $\begin{array}{c}12 \\
(6.7)\end{array}$ & $\begin{array}{c}9 \\
(36.0)\end{array}$ & \\
\hline Tumor recurrence & & & $<0.001$ & & & $<0.001$ & & & 0.025 & & & 0.105 & & & $<0.001$ \\
\hline Absent & $\begin{array}{c}157 \\
(95.2)\end{array}$ & $\begin{array}{c}28 \\
(73.7)\end{array}$ & & $\begin{array}{c}148 \\
(95.5)\end{array}$ & $\begin{array}{c}37 \\
(77.1)\end{array}$ & & $\begin{array}{c}171 \\
(92.9)\end{array}$ & $\begin{array}{c}14 \\
(73.7)\end{array}$ & & $\begin{array}{c}83 \\
(96.5)\end{array}$ & $\begin{array}{c}102 \\
(87.2)\end{array}$ & & $\begin{array}{c}167 \\
(93.8)\end{array}$ & $\begin{array}{c}18 \\
(72.0)\end{array}$ & \\
\hline Present & $\begin{array}{c}8 \\
(4.8)\end{array}$ & $\begin{array}{c}10 \\
(26.3)\end{array}$ & & $\begin{array}{c}7 \\
(4.5)\end{array}$ & $\begin{array}{c}11 \\
(22.9)\end{array}$ & & $\begin{array}{c}13 \\
(7.1)\end{array}$ & $\begin{array}{c}5 \\
(26.3)\end{array}$ & & $\begin{array}{c}3 \\
(3.5)\end{array}$ & $\begin{array}{c}15 \\
(12.8)\end{array}$ & & $\begin{array}{c}11 \\
(6.2)\end{array}$ & $\begin{array}{c}7 \\
(28.0)\end{array}$ & \\
\hline Distant metastasis & & & 0.005 & & & $<0.001$ & & & 0.015 & & & 0.065 & & & 0.005 \\
\hline Absent & $\begin{array}{c}163 \\
(98.8)\end{array}$ & $\begin{array}{c}32 \\
(84.2)\end{array}$ & & $\begin{array}{c}154 \\
(99.4)\end{array}$ & $\begin{array}{c}41 \\
(85.4)\end{array}$ & & $\begin{array}{c}180 \\
(97.8)\end{array}$ & $\begin{array}{c}15 \\
(78.9)\end{array}$ & & $\begin{array}{c}86 \\
(100.0)\end{array}$ & $\begin{array}{c}109 \\
(93.2)\end{array}$ & & $\begin{array}{c}175 \\
(98.3)\end{array}$ & $\begin{array}{c}20 \\
(80.0)\end{array}$ & \\
\hline Present & $\begin{array}{c}2 \\
(1.2)\end{array}$ & $\begin{array}{c}6 \\
(15.8)\end{array}$ & & $\begin{array}{c}1 \\
(0.6)\end{array}$ & $\begin{array}{c}7 \\
(14.6)\end{array}$ & & $\begin{array}{c}4 \\
(2.2)\end{array}$ & $\begin{array}{c}4 \\
(21.1)\end{array}$ & & $\begin{array}{c}0 \\
(0.0)\end{array}$ & $\begin{array}{c}8 \\
(6.8)\end{array}$ & & $\begin{array}{c}3 \\
(1.7)\end{array}$ & $\begin{array}{c}5 \\
(20.0)\end{array}$ & \\
\hline
\end{tabular}

${ }^{*} P$-values are corrected for multiple testing using the Bonferroni correction.

HPF, high-powered fields; Abbreviations as in Table 1

Expression of proteins related to serine and glycine metabolism according to phyllodes tumor grade. The immunohistochemical analysis of TMA revealed that stromal expression of PHGDH, PSAT1, PSPH, SHMT1, and GLDC $(\mathrm{p}<0.001$, Figure 1$)$ and epithelial expression of SHMT1 $(\mathrm{p}=0.005)$ were associated with increasing histologic grade (Table 3). Additionally, we evaluated the association between expression of serine/glycine metabolism-related proteins and Ki-67 LI. Epithelial expression of PHGDH and PSPH was positively correlated with Ki-67 LI of epithelial component 
Table 7. Correlations between serine/glycine-related and glycolysis-related proteins expressed in the epithelial component of PT

\begin{tabular}{|c|c|c|c|c|c|c|c|c|c|}
\hline \multirow[t]{2}{*}{ Parameters } & \multicolumn{3}{|c|}{ Glut-1 } & \multicolumn{3}{|c|}{ CAIX } & \multicolumn{3}{|c|}{ MCT4 } \\
\hline & $\begin{array}{c}\text { Negative } \\
\mathrm{n}=180(\%)\end{array}$ & $\begin{array}{l}\text { Positive } \\
n=5(\%)\end{array}$ & $P$-value $\dagger$ & $\begin{array}{c}\text { Negative } \\
\mathrm{n}=107(\%)\end{array}$ & $\begin{array}{c}\text { Positive } \\
\mathbf{n}=78(\%)\end{array}$ & $P$-value $\dagger$ & $\begin{array}{c}\text { Negative } \\
\mathrm{n}=169(\%)\end{array}$ & $\begin{array}{c}\text { Positive } \\
n=16(\%)\end{array}$ & $P$-value $\dagger$ \\
\hline PHGDH (E) & & & 0.981 & & & 0.072 & & & 3.000 \\
\hline Negative & $58(32.2)$ & $0(0.0)$ & & $41(38.3)$ & $17(21.8)$ & & $53(31.4)$ & $5(31.3)$ & \\
\hline Positive & $122(67.8)$ & $5(100.0)$ & & $66(61.7)$ & $61(78.2)$ & & $116(68.6)$ & $11(68.8)$ & \\
\hline PHGDH (S) & & & 3.000 & & & 1.608 & & & 2.142 \\
\hline Negative & $152(84.4)$ & $5(100.0)$ & & $89(83.2)$ & $68(87.2)$ & & $144(85.2)$ & $13(81.3)$ & \\
\hline Positive & $28(15.6)$ & $0(0.0)$ & & $18(16.8)$ & $10(12.8)$ & & $25(14.8)$ & $3(18.8)$ & \\
\hline PSAT1 (E) & & & 0.177 & & & 1.377 & & & 1.305 \\
\hline Negative & $91(50.6)$ & $0(0.0)$ & & $50(46.7)$ & $41(52.6)$ & & $85(50.3)$ & $6(37.5)$ & \\
\hline Positive & $89(49.4)$ & $5(100.0)$ & & $57(53.3)$ & $37(47.4)$ & & $84(49.7)$ & $10(62.5)$ & \\
\hline PSAT1 (S) & & & 3.000 & & & 1.743 & & & 3.000 \\
\hline Negative & $143(79.4)$ & $4(80.0)$ & & $83(77.6)$ & $64(82.1)$ & & $134(79.3)$ & $13(81.3)$ & \\
\hline Positive & $37(20.6)$ & $1(20.0)$ & & $24(22.4)$ & $14(17.9)$ & & $35(20.7)$ & $3(18.8)$ & \\
\hline PSPH (E) & & & 3.000 & & & 0.306 & & & 2.379 \\
\hline Negative & $80(44.4)$ & $2(40.0)$ & & $53(49.5)$ & $29(37.2)$ & & $74(43.8)$ & $8(50.0)$ & \\
\hline Positive & $100(55.6)$ & $3(60.0)$ & & $54(50.5)$ & $49(62.8)$ & & $95(56.2)$ & $8(50.0)$ & \\
\hline PSPH (S) & & & 3.000 & & & 3.000 & & & 0.834 \\
\hline Negative & $168(93.3)$ & $5(100.0)$ & & $100(93.5)$ & $73(93.6)$ & & $159(94.1)$ & $14(87.5)$ & \\
\hline Positive & $12(6.7)$ & $0(0.0)$ & & $7(6.5)$ & $5(6.4)$ & & $10(5.9)$ & $2(12.5)$ & \\
\hline SHMT1 (E) & & & 0.072 & & & 0.099 & & & 0.234 \\
\hline Negative & $131(72.8)$ & $1(20.0)$ & & $83(77.6)$ & $49(62.8)$ & & $124(73.4)$ & $8(50.0)$ & \\
\hline Positive & $49(27.2)$ & $4(80.0)$ & & $24(22.4)$ & $29(37.2)$ & & $45(26.6)$ & $8(50.0)$ & \\
\hline SHMT1 (S) & & & 1.971 & & & 0.159 & & & 0.363 \\
\hline Negative & $79(43.9)$ & $3(60.0)$ & & $54(50.5)$ & $28(35.9)$ & & $78(46.2)$ & $4(25.0)$ & \\
\hline Positive & $101(56.1)$ & $2(40.0)$ & & $53(49.5)$ & $50(64.1)$ & & $91(53.8)$ & $12(75.0)$ & \\
\hline GLDC (E) & & & 3.000 & & & 0.027 & & & 2.055 \\
\hline Negative & $20(11.1)$ & $0(0.0)$ & & $17(15.9)$ & $3(3.8)$ & & $18(10.7)$ & $2(12.5)$ & \\
\hline Positive & $160(88.9)$ & $5(100.0)$ & & $90(84.1)$ & $75(96.2)$ & & $151(89.3)$ & $14(87.5)$ & \\
\hline GLDC (S) & & & 3.000 & & & 3.165 & & & 0.195 \\
\hline Negative & $161(89.4)$ & $5(100.0)$ & & $97(90.7)$ & $69(88.5)$ & & $154(91.1)$ & $12(75.0)$ & \\
\hline Positive & $19(10.6)$ & $0(0.0)$ & & $10(9.3)$ & $9(11.5)$ & & $15(8.9)$ & $4(25.0)$ & \\
\hline
\end{tabular}

${ }^{*}$ Eighteen cases without an epithelial component were excluded.

$\uparrow P$-values are corrected for multiple testing using the Bonferroni correction.

( $p=0.019$, and 0.005 , respectively), and stromal expression of PHGDH $(\mathrm{p}<0.001)$, PSAT1 $(\mathrm{p}<0.001)$, SHMT1 $(\mathrm{p}=0.002)$ and GLDC $(\mathrm{p}<0.01)$ was positively correlated with Ki-67 LI of stromal component (Table 4).

Correlations between serine and glycine-related proteins expressed in phyllodes tumor and pathologic parameters. In this set of patients with PT, PHGDH expression in epithelial component was correlated with infiltrative tumor margin $(\mathrm{p}=0.045)$, and SHMT1 expression in epithelial component was correlated with increased stromal atypia $(\mathrm{p}=0.005)$, increased stromal mitosis $(\mathrm{p}=0.010)$, and tumor recurrence $(\mathrm{p}=0.015)$ (Table 5).

In stromal regions of these PTs, expression of $\mathrm{PHGDH}$, PSAT1, PSPH, SHMT1, and GLDC were all correlated with increased stromal cellularity, increased stromal atypia, increased mitosis, stromal overgrowth, and infiltrative tumor margin $(\mathrm{p}<0.05)$. In addition, PHGDH, PSAT1, PSPH, and GLDC expressions were correlated with tumor recurrence and distant metastasis $(\mathrm{p}<0.05$, Table 6$)$.

Correlations between serine and glycine-related and glycolysis-related proteins expressed in PT. Previously we reported on expression of glycolysis-related proteins Glut-1, CAIX, and MCT4 [9]. In this study, we investigated associations between expression of Glut-1, CAIX, and MCT4 and expression of proteins involved in serine and glycine metabolism. In epithelial portions of the tumors we found no correlations (Table 7). Within stromal regions, MCT4 expression was correlated with stromal PHGDH $(\mathrm{p}<0.001)$, 
Table 8. Correlations between serine/glycine-related and glycolysis-related proteins expressed in the stromal component of PT

\begin{tabular}{|c|c|c|c|c|c|c|c|c|c|}
\hline \multirow[t]{2}{*}{ Parameters } & \multicolumn{3}{|c|}{ Glut-1 } & \multicolumn{3}{|c|}{ CAIX } & \multicolumn{3}{|c|}{ MCT4 } \\
\hline & $\begin{array}{c}\text { Negative } \\
\mathrm{n}=198(\%)\end{array}$ & $\begin{array}{c}\text { Positive } \\
\mathrm{n}=5(\%)\end{array}$ & $P$-value ${ }^{*}$ & $\begin{array}{c}\text { Negative } \\
\mathrm{n}=142(\%)\end{array}$ & $\begin{array}{c}\text { Positive } \\
\mathrm{n}=61(\%)\end{array}$ & $P$-value ${ }^{*}$ & $\begin{array}{c}\text { Negative } \\
\mathrm{n}=173(\%)\end{array}$ & $\begin{array}{c}\text { Positive } \\
\mathrm{n}=\mathbf{3 0}(\%)\end{array}$ & $P$-value ${ }^{*}$ \\
\hline PHGDH $(\mathrm{E})^{*}$ & & & $\mathrm{n} / \mathrm{a}$ & & & 0.195 & & & 3.000 \\
\hline Negative & $58(31.4)$ & $0(0.0)$ & & $46(34.6)$ & $12(23.1)$ & & $53(31.7)$ & $5(27.8)$ & \\
\hline Positive & $127(68.6)$ & $0(0.0)$ & & $87(65.4)$ & $40(76.9)$ & & $114(68.3)$ & $13(72.2)$ & \\
\hline PHGDH (S) & & & 0.138 & & & 0.051 & & & $<0.001$ \\
\hline Negative & $163(82.3)$ & $2(40.0)$ & & $122(85.9)$ & $43(70.5)$ & & $150(86.7)$ & $15(50.0)$ & \\
\hline Positive & $35(17.7)$ & $3(60.0)$ & & $20(14.1)$ & $18(29.5)$ & & $23(13.3)$ & $15(50.0)$ & \\
\hline PSAT1 $(E)^{*}$ & & & $\mathrm{n} / \mathrm{a}$ & & & 0.744 & & & 3.000 \\
\hline Negative & $91(49.2)$ & $0(0.0)$ & & $64(48.1)$ & $27(51.9)$ & & $82(49.1)$ & $9(50.0)$ & \\
\hline Positive & $94(50.8)$ & $0(0.0)$ & & 69 (51.9) & $25(48.1)$ & & $85(50.9)$ & $9(50.0)$ & \\
\hline PSAT1 (S) & & & 0.261 & & & 0.147 & & & $<0.001$ \\
\hline Negative & $153(77.3)$ & $2(40.0)$ & & $114(80.3)$ & $41(67.2)$ & & $141(81.5)$ & $14(46.7)$ & \\
\hline Positive & $45(22.7)$ & $3(60.0)$ & & $28(19.7)$ & $20(32.8)$ & & $32(18.5)$ & $16(53.3)$ & \\
\hline $\operatorname{PSPH}(\mathrm{E})^{*}$ & & & $\mathrm{n} / \mathrm{a}$ & & & 0.150 & & & 1.365 \\
\hline Negative & $82(44.3)$ & $0(0.0)$ & & $65(48.9)$ & $17(32.7)$ & & $76(45.5)$ & $6(33.3)$ & \\
\hline Positive & $103(55.7)$ & $0(0.0)$ & & $68(51.1)$ & $35(67.3)$ & & $91(54.5)$ & $12(66.7)$ & \\
\hline PSPH (S) & & & 0.210 & & & 0.102 & & & $<0.001$ \\
\hline Negative & $181(91.4)$ & $3(60.0)$ & & $133(93.7)$ & $51(83.6)$ & & $163(64.2)$ & $21(70.0)$ & \\
\hline Positive & $17(8.6)$ & $2(40.0)$ & & $9(6.3)$ & $10(16.4)$ & & $10(5.8)$ & $9(30.0)$ & \\
\hline SHMT1 $(E)^{*}$ & & & $\mathrm{n} / \mathrm{a}$ & & & 1.416 & & & 0.156 \\
\hline Negative & $132(71.4)$ & $0(0.0)$ & & 97 (72.9) & $35(67.3)$ & & $123(73.7)$ & $9(50.0)$ & \\
\hline Positive & $53(28.6)$ & $0(0.0)$ & & $36(27.1)$ & $17(32.7)$ & & $44(26.3)$ & $9(50.0)$ & \\
\hline SHMT1 (S) & & & 1.194 & & & $<0.001$ & & & $<0.001$ \\
\hline Negative & 85 (42.9) & $1(20.0)$ & & $77(54.2)$ & $9(14.8)$ & & $82(47.4)$ & $4(13.3)$ & \\
\hline Positive & $113(57.1)$ & $4(80.0)$ & & $65(45.8)$ & $52(85.2)$ & & $91(52.6)$ & $26(86.7)$ & \\
\hline $\operatorname{GLDC}(\mathrm{E})^{*}$ & & & $\mathrm{n} / \mathrm{a}$ & & & 0.594 & & & 1.257 \\
\hline Negative & $20(10.8)$ & $0(0.0)$ & & $17(12.8)$ & $3(5.8)$ & & $17(10.2)$ & $3(16.7)$ & \\
\hline Positive & $165(89.2)$ & $0(0.0)$ & & $116(87.2)$ & 49 (94.2) & & $150(89.8)$ & $15(83.3)$ & \\
\hline GLDC (S) & & & 0.042 & & & $<0.001$ & & & 0.003 \\
\hline Negative & $176(88.9)$ & $2(40.0)$ & & $134(94.4)$ & $44(72.1)$ & & $158(91.3)$ & $20(66.7)$ & \\
\hline Positive & $22(11.1)$ & $3(60.0)$ & & $8(5.6)$ & 17 (27.9) & & $15(8.7)$ & $10(33.3)$ & \\
\hline
\end{tabular}

${ }^{*} P$-values are corrected for multiple testing using the Bonferroni correction.

E, epithelial; S, stromal, Glut1, glucose transporter 1; CAIX, carbonic anhydrase; MTC4, monocarboxylate transporter 4; other enzymes as in Table 1

stromal PSAT1 $(\mathrm{p}<0.001)$, stromal PSPH $(\mathrm{p}<0.001)$, stromal SHMT1 $(\mathrm{p}<0.001)$, and stromal GLDC $(\mathrm{p}=0.006)$ expression. In addition, stromal CAIX expression correlated with stromal SHMT1 and stromal GLDC expression $(\mathrm{p}<0.001$, Table 8).

Associations of serine and glycine-related protein expression with patient outcome in PT. In univariate analysis, positive staining for stromal PHGDH $(\mathrm{p}<0.001)$, stromal PSAT1 $(p<0.001)$, stromal PSPH $(p=0.003)$, epithelial SHMT1 $(\mathrm{p}=0.001)$, stromal SHMT1 $(\mathrm{p}=0.022)$, and stromal GLDC $(\mathrm{p}<0.001)$ in the PT were associated with shorter disease-free survival (DFS) (Table 9). Positive staining for stromal GLDC in the PT was associated with shorter overall survival (OS) $(\mathrm{p}<0.001$, Figure 4). Multivariate Cox analysis revealed no factor independently associated with shorter DFS or shorter OS (Table 10).

\section{Discussion}

A principal finding in this study was that stromal expression of proteins related to serine and glycine metabolism increased in phyllodes tumors with increasing histologic tumor grade. Although we found no previous study appropriate for comparison, reported associations of PHGDH with breast carcinoma [4] and melanoma [3], and of GLDC with tumor aggressiveness in pulmonary non-small cell carcinoma [5], are compatible with our results. In a previous study we found that stromal expression of the glycolysis-related proteins 
Table 9. Univariate analysis of serine- and glycine-related proteins expressed with respect to patient prognosis using the log-rank test

\begin{tabular}{|c|c|c|c|c|c|}
\hline \multirow[t]{2}{*}{ Parameters } & \multirow{2}{*}{$\begin{array}{c}\text { No. of patients } \\
\text { Total/recurrence/metastasis }\end{array}$} & \multicolumn{2}{|c|}{ Disease-free survival } & \multicolumn{2}{|c|}{ Overall survival } \\
\hline & & $\begin{array}{l}\text { Median survival } \\
(95 \% \mathrm{CI}) \text { months }\end{array}$ & $P$-value & $\begin{array}{l}\text { Median survival } \\
(95 \% \mathrm{CI}) \text { months }\end{array}$ & $P$-value \\
\hline PHGDH (E) & & & 0.222 & & $\mathrm{n} / \mathrm{a}$ \\
\hline Negative & $58 / 2 / 0$ & $172(164-181)$ & & $\mathrm{n} / \mathrm{a}$ & \\
\hline Positive & $127 / 10 / 2$ & $168(159-177)$ & & $\mathrm{n} / \mathrm{a}$ & \\
\hline PHGDH (S) & & & $<0.001$ & & 0.527 \\
\hline Negative & $165 / 8 / 6$ & $174(168-180)$ & & $176(171-181)$ & \\
\hline Positive & $38 / 10 / 2$ & $102(83-122)$ & & $133(123-142)$ & \\
\hline PSAT1 (E) & & & 0.165 & & 0.846 \\
\hline Negative & $91 / 4 / 1$ & $169(162-176)$ & & $175(171-178)$ & \\
\hline Positive & $94 / 8 / 1$ & $166(154-177)$ & & $179(173-186)$ & \\
\hline PSAT1 (S) & & & $<0.001$ & & 0.268 \\
\hline Negative & $155 / 7 / 5$ & $174(169-180)$ & & $177(172-182)$ & \\
\hline Positive & $48 / 11 / 3$ & $103(86-119)$ & & $127(118-135)$ & \\
\hline PSPH (E) & & & 0.129 & & 0.947 \\
\hline Negative & $82 / 3 / 1$ & $176(168-183)$ & & $180(176-185)$ & \\
\hline Positive & $103 / 9 / 1$ & $161(151-171)$ & & $175(172-178)$ & \\
\hline PSPH (S) & & & 0.003 & & 0.094 \\
\hline Negative & $184 / 13 / 6$ & $170(163-176)$ & & $177(172-181)$ & \\
\hline Positive & $19 / 5 / 2$ & $72(55-89)$ & & $86(74-97)$ & \\
\hline SHMT1 (E) & & & 0.001 & & $\mathrm{n} / \mathrm{a}$ \\
\hline Negative & $132 / 4 / 5$ & $177(172-182)$ & & $\mathrm{n} / \mathrm{a}$ & \\
\hline Positive & $53 / 8 / 0$ & $148(130-166)$ & & $\mathrm{n} / \mathrm{a}$ & \\
\hline SHMT1 (S) & & & 0.022 & & 0.077 \\
\hline Negative & $86 / 3 / 1$ & $176(169-183)$ & & $181(177-184)$ & \\
\hline Positive & $117 / 15 / 7$ & $156(145-167)$ & & $168(160-176)$ & \\
\hline GLDC (E) & & & 0.526 & & $\mathrm{n} / \mathrm{a}$ \\
\hline Negative & $20 / 2 / 0$ & $153(132-174)$ & & $\mathrm{n} / \mathrm{a}$ & \\
\hline Positive & $165 / 10 / 2$ & $171(165-178)$ & & $\mathrm{n} / \mathrm{a}$ & \\
\hline GLDC (S) & & & $<0.001$ & & 0.001 \\
\hline Negative & $178 / 11 / 4$ & $171(165-178)$ & & $178(174-182)$ & \\
\hline Positive & $25 / 7 / 4$ & $104(78-129)$ & & $123(103-142)$ & \\
\hline
\end{tabular}

Abbreviations: S, stromal component; E, epithelial component; enzymes as in Table 1

${ }^{a} 14$ cases without an epithelial component were excluded.

glucose transporter-1 (Glut-1), carbonic anhydrase (CAIX), and monocarboxylate transporter 4 (MCT4) increased with increasing tumor grade in PT [9], consistent with an increase in demand for energy and anabolic substrates. Results in the present study confirmed a similar increase in serine and glycine metabolism with tumor grade. In addition, we observed an association between glycolysis-related proteins and proteins related to serine and glycine metabolism, consistent with the interdependence of these pathways. Specifically, expression of the glycolysis-related proteins CAIX and MCT4 in stromal regions of PT were significantly correlated with stromal expression of proteins related to serine and glycine metabolism.

A previous study suggested that increased biosynthesis of serine influences breast cancer behavior through production of $a$-ketoglutarate, a TCA cycle intermediate, rather than by other conversions of serine [4]. This may result in suggestion that the increased glycolysis and increased serine metabolism that we observed in phyllodes tumor, as products of these pathways feed into mitochondrial metabolism. Studies on the expression of ATP synthase, glutaminase 1 (GLS1) and succinate dehydrogenase (SDH) may resolve this question.

In this study, increased stromal expression of SHMT1 in PT with increasing histologic grade is consistent with a role for glycine in rapid cancer cell proliferation as previously reported [2]. In the epithelial component of PT, only SHMT1 among serine/glycine metabolism-related proteins showed increased expression with increasing tumor grade. Although malignant PTs may occasionally display vigorous stromal proliferation resulting in no identifiable epithelial component, 
Table 10. Multivariate analysis of disease-free survival in patients with phyllodes tumors

\begin{tabular}{|c|c|c|c|c|c|c|}
\hline \multirow[t]{2}{*}{ Included factor } & \multicolumn{3}{|c|}{ Disease-free survival } & \multicolumn{3}{|c|}{ Overall-survival } \\
\hline & Hazard ratio & $95 \% \mathrm{CI}$ & $P$-value & Hazard ratio & $95 \% \mathrm{CI}$ & $P$-value \\
\hline Histologic grade & & & 0.219 & & & 1.000 \\
\hline Benign vs. Borderline or Malignant & 7.923 & $0.293-214.2$ & & 1.000 & $0.018-57.02$ & \\
\hline Stromal cellularity & & & 0.897 & & & 1.000 \\
\hline Mild vs. moderate or marked & 0.852 & $0.076-9.554$ & & 1.000 & $0.141-7.094$ & \\
\hline Stromal atypia & & & 0.239 & & & 1.000 \\
\hline Mild vs. moderate or marked & 0.195 & $0.013-2.962$ & & 1.000 & $0.024-43.71$ & \\
\hline Stromal mitosis & & & 0.200 & & & 1.000 \\
\hline $0-4 / 10$ HPFs vs. $>4 / 10$ HPFs & 5.867 & $0.392-87.93$ & & 1.000 & $0.023-43.71$ & \\
\hline Stromal overgrowth & & & 0.077 & & & 1.000 \\
\hline Absent vs. Present & 10.872 & $0.774-152.6$ & & 1.000 & $0.016-61.74$ & \\
\hline Tumor margin & & & 0.361 & & & 1.000 \\
\hline Circumscribed vs. Infiltrative & 0.298 & $0.022-3.991$ & & 1.000 & $0.050-19.94$ & \\
\hline PHGDH (S) & & & 0.472 & & Not included & \\
\hline Negative vs. Positive & 2.061 & $0.288-14.76$ & & & & \\
\hline PSAT1 (S) & & & 0.942 & & Not included & \\
\hline Negative vs. Positive & 0.936 & $0.159-5.511$ & & & & \\
\hline PSPH (S) & & & 0.573 & & & 1.000 \\
\hline Negative vs. Positive & 0.552 & $0.070-4.349$ & & 1.000 & $0.060-16.73$ & \\
\hline SHMT1 (E) & & & 0.060 & & Not included & \\
\hline Negative vs. Positive & 4.783 & $0.939-24.37$ & & & & \\
\hline SHMT1 (S) & & & 0.330 & & & 1.000 \\
\hline Negative vs. Positive & 0.343 & $0.040-2.953$ & & 1.000 & $0.205-4.885$ & \\
\hline GLDC (S) & & & 0.088 & & & 1.000 \\
\hline Negative vs. Positive & 5.145 & $0.782-33.84$ & & 1.000 & $0.084-11.83$ & \\
\hline
\end{tabular}

Abbreviations: HPFs, high-power fields; S, stromal component; E, epithelial component; enzymes as in Table 1.

epithelial proliferation, when present, is more often observed in borderline PTs than in benign ones, suggesting that singlecarbon metabolism may influence progression in the epithelial component of PT.

The GLDC expression also increased with increasing histologic grade in this set of phyllodes tumors. The exact mechanism for this is unknown; however, it may possibly be explained as a secondary effect of oncogene overexpression. The expression of GLDC is shown to increase in cultured breast epithelial cells following transformation by KRAS, PIK3CA and MYC oncogenes (MCF10A) [5], and stromal c-myc [11] and EGFR [12] expression may increase with increasing histologic grade in PTs.

Our results demonstrating the significant association between stromal expression of serine/glycine metabolism-related proteins of $\mathrm{PT}$ and poor prognosis are consistent with the results of previous studies; PHGDH expression and GLDC expression were reported to be correlated with poor prognosis in cervical cancer [13] and lung cancer [5], respectively. Expression of glycolysis-related proteins such as Glut-1[14, 15], CAIX[16, 17], MCT-4[18-21] was reported to be associated with poor prognosis in various type of cancer, indicating that increased glycolysisrelated metabolism has a correlation with poor prognosis.
Based on the roles of serine and glycine in single-carbon metabolism, increased stromal expression of enzymes that metabolize these amino acids with increasing histologic grade in PTs may have therapeutic significance. Ongoing preclinical studies of drugs targeting multiple sites of one-carbon metabolism, including GLDC, PSAT, PSPH, PHGDH, may yield new possibilities for the therapy of PTs $[14,22]$.

In conclusion, expression of proteins related to serine and glycine metabolism increased in the stromal component of phyllodes tumor with increasing tumor histologic grade, and expression of these proteins correlated with expression of the glycolysis-related proteins CAIX, and MCT4.

Acknowledgements: This research was supported by a grant (2012R1A1A1002886) from the Basic Science Research Program through the National Research Foundation of Korea (NRF) funded by the Ministry of Education, Science and Technology.

\section{References}

[1] WARBURG O On the origin of cancer cells. Science 1956; 123: 309-14. http://dx.doi.org/10.1126/science.123.3191.309 
[2] JAIN M, NILSSON R, SHARMA S, MADHUSUDHAN N, KITAMI $\mathrm{T}$ et al. Metabolite profiling identifies a key role for glycine in rapid cancer cell proliferation. Science 2012; 336: 1040-1044. http://dx.doi.org/10.1126/science.1218595

[3] MULLARKY E, MATTAINI KR, VANDER HEIDEN MG, CANTLEY LC, LOCASALE JW PHGDH amplification and altered glucose metabolism in human melanoma. Pigment Cell Melanoma Res 2011; 24: 1112-1115. http://dx.doi. org/10.1111/j.1755-148X.2011.00919.x

[4] POSSEMATO R, MARKS KM, SHAUL YD, PACOLD ME, KIM D et al. Functional genomics reveal that the serine synthesis pathway is essential in breast cancer. Nature 2011; 476: 346-350. http://dx.doi.org/10.1038/nature10350

[5] ZHANG WC, SHYH-CHANG N, YANG H, RAI A, UMASHANKAR $S$ et al. Glycine decarboxylase activity drives non-small cell lung cancer tumor-initiating cells and tumorigenesis. Cell 2012; 148: 259-272. http://dx.doi. org/10.1016/j.cell.2011.11.050

[6] ANDERSON B, LAWTON T, LEHMAN C, MOE R Phyllodes tumor. In: Morrow M, Osborne C, editors. Disease of the Breast. Philadelphia: Lippincott \& Wilkins, 2004: 991-1006.

[7] TAVASSOLI FA DP World Heath Organization Classification of Tumors. Lyon: IARC Press, 2003.

[8] BEN HASSOUNA J, DAMAK T, GAMOUDI A, CHARGUI R, KHOMSI F et al. Phyllodes tumors of the breast: a case series of 106 patients. Am J Surg 2006; 192: 141-147. http://dx.doi. org/10.1016/j.amjsurg.2006.04.007

[9] KWON JE, JUNG WH, KOO JS. The expression of metabolism-related proteins in phyllodes tumors. Tumour Biol 2013; 34: 115-124. http://dx.doi.org/10.1007/s13277-012-0518-9

[10] WON KY, KIM GY, KIM YW, SONG JY, LIM SJ. Clinicopathologic correlation of beclin-1 and bcl-2 expression in human breast cancer. Hum Pathol 2010; 41: 107-112. http://dx.doi. org/10.1016/j.humpath.2009.07.006

[11] SAWYER EJ, POULSOM R, HUNT FT, JEFFERY R, ELIA G et al. Malignant phyllodes tumours show stromal overexpression of c-myc and c-kit. J Pathol 2003; 200: 59-64. http://dx.doi. org/10.1002/path.1318

[12] KERSTING C, KUIJPER A, SCHMIDT H, PACKEISEN J, LIEDTKE $\mathrm{C}$ et al. Amplifications of the epidermal growth factor receptor gene (egfr) are common in phyllodes tumors of the breast and are associated with tumor progression. Lab Invest 2006; 86: 54-61. http://dx.doi.org/10.1038/ labinvest. 3700358

[13] JING Z, HENG W, AIPING D, YAFEI Q, SHULAN Z. Expression and clinical significance of phosphoglycerate dehydrogenase and squamous cell carcinoma antigen in cervical cancer. Int J Gynecol Cancer 2013; 23: 1465-1469. http://dx.doi.org/10.1097/IGC.0b013e3182a0c068

[14] CHO H, LEE YS, KIM J, CHUNG JY, KIM JH. Overexpression of glucose transporter-1 (GLUT-1) predicts poor prognosis in epithelial ovarian cancer. Cancer Invest 2013; 31: 607-615. http://dx.doi.org/10.3109/07357907.2013.849722

[15] KIM K, PARK WY, KIM JY, SOL MY, SHIN DH et al. Prognostic Relevance of the Expression of CA IX, GLUT-1, and VEGF in Ovarian Epithelial Cancers. Korean J Pathol 2012; 46: 532-540. http://dx.doi.org/10.4132/KoreanJPathol.2012. 46.6.532

[16] KLIMOWICZ AC, BOSE P, PETRILLO SK, MAGLIOCCO AM, DORT JC et al. The prognostic impact of a combined carbonic anhydrase IX and Ki67 signature in oral squamous cell carcinoma. Br J Cancer 2013; 109: 1859-1866. http://dx.doi. org/10.1038/bjc.2013.533

[17] LIU Z, YANG Z, JIANG S, ZOU Q, YUAN Y et al. Paxillin and Carbonic Anhydrase IX are prognostic markers in gallbladder squamous cell/adenosquamous carcinomas and adenocarcinomas. Histopathology 2013.

[18] GOTANDA Y, AKAGI Y, KAWAHARA A, KINUGASA T, YOSHIDA T et al. Expression of monocarboxylate transporter (MCT) 4 in colorectal cancer and its role: MCT4 contributes to the growth of colorectal cancer with vascular endothelial growth factor. Anticancer Res 2013; 33: 2941-2947.

[19] MEIJER TW, SCHUURBIERS OC, KAANDERS JH, LOOIJEN-SALAMON MG, DE GEUS-OEI LF et al. Differences in metabolism between adeno- and squamous cell non-small cell lung carcinomas: spatial distribution and prognostic value of GLUT1 and MCT4. Lung Cancer 2012; 76: 316-323. http:// dx.doi.org/10.1016/j.lungcan.2011.11.006

[20] NAKAYAMA Y, TORIGOE T, INOUE Y, MINAGAWA N, IZUMI $\mathrm{H}$ et al. Prognostic significance of monocarboxylate transporter 4 expression in patients with colorectal cancer. Exp Ther Med 2012; 3: 25-30.

[21] PERTEGA-GOMES N, VIZCAINO JR, MIRANDA-GONCALVES V, PINHEIRO C, SILVA J et al. Monocarboxylate transporter 4 (MCT4) and CD147 overexpression is associated with poor prognosis in prostate cancer. BMC Cancer 2011; 11: 312. http://dx.doi.org/10.1186/1471-2407-11-312

[22] YANG C, SUDDERTH J, DANG T, BACHOO RM, MCDONALD JG et al. Glioblastoma cells require glutamate dehydrogenase to survive impairments of glucose metabolism or Akt signaling. Cancer Res 2009; 69: 7986-7993. http:// dx.doi.org/10.1158/0008-5472.CAN-09-2266 